\title{
Propagation and Extinction of a Cylindrical Premixed Flame Undergoing Equivalence Ratio Fluctuation Near the Lean Limit"
}

\author{
Yosuke SUENAGA $^{* *}$, Michio KITANO ${ }^{* * *}$ and Yoichi TAKAHASHI ${ }^{* * * *}$ \\ **Hachinohe National College of Technology, \\ 16-1 Uwanotai, Tamonoki, Hachinohe-shi, Aomori 039-1192, Japan \\ E-mail: suenaga-m@hachinohe-ct.ac.jp \\ ***Iwate University, \\ 4-3-5 Ueda, Morioka-shi, Iwate 020-8551, Japan \\ ****Asaka R\&D Center, Honda R\&D Co., Ltd., \\ 3-15-1 Senzui, Asaka-shi, Saitama 351-8555, Japan
}

\begin{abstract}
Experimental study was made to investigate the propagation and extinction characteristics of a stretched cylindrical flame undergoing periodic fluctuation of equivalence ratio near the lean limit. With a lean methane-air and a lean propane-air mixture, burning velocity, flame luminosity and flame stretch rate were measured or evaluated for the fluctuation frequencies of $5 \mathrm{~Hz}$ and $20 \mathrm{~Hz}$. The results were summarized as follows: (1) In some part of a period, burning velocity and flame luminosity of the dynamic flame near the lean limit were possible to become lower than those at the lean flammability limit of the static flame. (2) At the high frequency of $20 \mathrm{~Hz}$, the burning velocity took a negative value in a certain time range. In spite of this loss of propagation ability, the flame was not extinguished but sustained, indicating the recovery of the flame intensity due to the dynamic effect of fluctuating flame. (3) Flame recovery phenomenon could occur more easily for the methane flame which was strengthened by the Lewis number effect than the propane flame which was weakened by that effect.
\end{abstract}

Key words: Premixed Combustion, Flammability Limit, Extinction, Equivalence Ratio Fluctuation, Cylindrical Flame, Burning Velocity, Flame Luminosity

\section{Introduction}

Turbulent flame is used for most of the practical combustors. Laminar Flamelet Concept ${ }^{(1)}$, in which the local structure of this turbulent flame is regarded as an aggregation of laminar flamelets that have a curvature and are subject to stretch and contraction, was proposed in a previous study. Many relevant studies have been performed ${ }^{(2)-(10)}$.

Although the turbulent flame may be locally extinguished depending on its degree of stretch or curvature, there are fundamental studies about such local structure of the turbulent premixed flame: studies about extinction of planar flame in the stagnation-flow field or counterflow field, where the flame is only affected by $\operatorname{stretch}^{(2),(3)}$; and studies about extinction of cylindrical flame, where the flame is affected by both stretch and curvature, simultaneously $^{(4),(5)}$. Based on these studies, it has been found that the extinction may be classified into two types depending on the Lewis number of deficient reactants in the

*Received 30 Apr., 2010 (No. T2-06-0981) Japanese Original : Trans. Jpn. Soc. Mech. Eng., Vol.73, No.731, B (2007), pp.1562-1569 (Recieved 25 Sep., 2006) [DOI: 10.1299/jtst.5.124]

Copyright $(\mathcal{C} 2010$ by JSME 
mixture, and that the flammability limit of the flame may vary with the Lewis number or the flame curvature even when the flame is stretched to the same degree.

Recently, focus has been on fluctuations, which is a characteristic of turbulence, and studies about response of the stagnation-flow or counterflow premixed flame, when velocity fluctuations or concentration fluctuations are given to the mixture flow, are being conducted. Egolfopoulos ${ }^{(6)}$ numerically studied about the response of the counterflow flame when sinusoidally changing the velocity by blowing the mixture out, and made it clear that the partially extinguished flame is reignited and the extinction delays when the velocity is fluctuated at a high frequency. He also found that the extinction may be completely prevented at a further high-fluctuation frequency. Hirasawa et al. ${ }^{(7)}$ studied about the burning velocity of the wall stagnation-flow flame when the wall position is sinusoidally fluctuated, and showed that the fluctuation amplitude of the burning velocity increased as the frequency increased. As for the studies about concentration fluctuations, on the other hand, Marzouk et al. ${ }^{(8)}$ numerically studied about the response of the stagnation-flow flame when changing equivalence ratio from stoichiometric to lean, while Lauvergne and Egolfopoulos ${ }^{(9)}$ and Sankaran and $\operatorname{Im}^{(10)}$ numerically studied about the flame response when equivalence ratio sinusoidally fluctuated in the lean range. Accordingly, it has been shown that the lean flammability limit further extends toward the lean side.

As seen above, areas of studies about the response of the stretch premixed flame in a flow field of the stagnation-flow type is expanding from the steady flame to the unsteady combustion, in which the velocity or concentration of the mixture fluctuates. Based on this background, we have experimentally studied about the response of the wall stagnation-flow premixed flame and cylindrical outwardly propagating flame to periodic equivalence ratio fluctuations $^{(11)-(14)}$. Accordingly, we made it clear that for methane/air flame, the fluctuation amplitudes of burning velocity, burnt gas temperature, burnt gas composition, and luminosity of the flame with concentration fluctuations (dynamic flame) become larger than the variation width, which could be estimated from the range of equivalence ratio of the flame without fluctuations (static flame). Moreover, we showed that fluctuations of the flame curvature also affect the increase in the fluctuation amplitudes in the case of cylindrical flame. Hence, in this study, we use the cylindrical flame, and to find out an effect of increase in the fluctuation amplitude on the flammability limit, we study the characteristics of propagation and extinction of the flame near the lean flammability limit when the equivalence ratio fluctuates. Furthermore, we discuss the Lewis number effect on extinction of the dynamic flame.

\section{Experimental setup and procedure}

\subsection{Combustor}

Fig. 1 shows an overview of the cylindrical-flame burner used in this experiment. Its structure can fluctuate the concentration (equivalence ratio) in the main flow direction, i.e., the direction vertical to the flame surface, while maintaining a constant mixture flow rate. A porous sintered metal cylinder of $16-\mathrm{mm}$ inner diameter, $70-\mathrm{mm}$ length, and $20-\mu \mathrm{m}$ filtration diameter was set horizontally in the central section of the burner. The mixture was uniformly percolated toward the central axis through the porous wall from the central $20 \mathrm{~mm}$ of the cylinder. Nitrogen was supplied from the two ends of the cylinder, each 15 $\mathrm{mm}$ in length, to isolate the flame from the ambient air.

\subsection{Gas supplying system}

Fig. 2 shows a schematic of the gas supplying system. The concentration of the mixture is fluctuated in the mixing chamber placed upstream of the burner. First, the primary mixture with a constant flow rate and concentration is supplied. Next, secondary fuel and secondary air, which generate concentration fluctuations, are alternately supplied to the 
mixture using solenoid valves. Thus, the flow of the mixture blowing out from the burner can be kept constant, and the equivalence ratio can be fluctuated only in the vertical direction to the flame surface. Percolation rate $U$ of the mixture is $40 \mathrm{~cm} / \mathrm{sec}$.

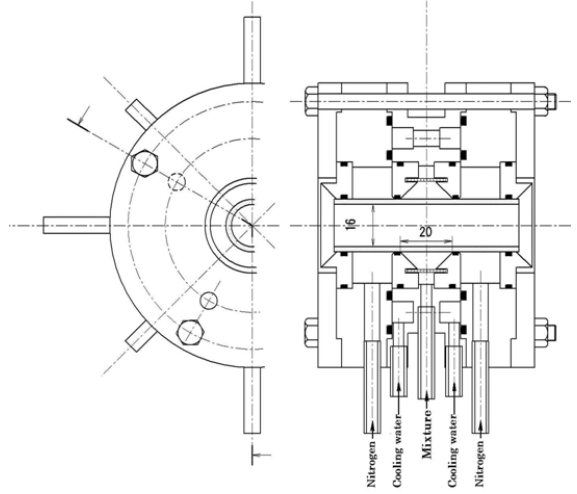

Fig. 1 Cylindrical flame burner

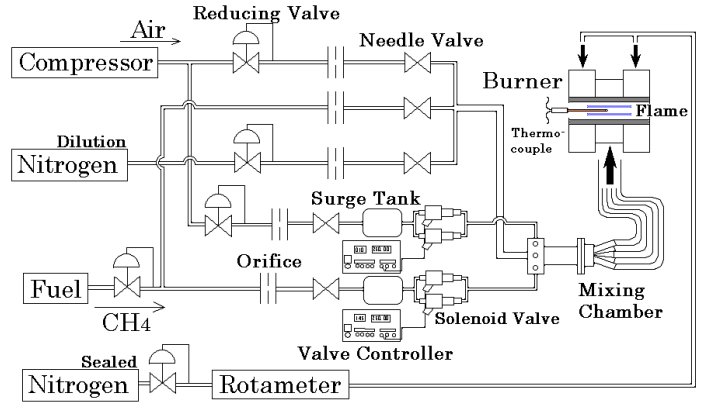

Fig. 2 Schematic of gas-supplying system

Methane and propane were used as fuel, and air was used as an oxidant. The 3.39- $\mu \mathrm{m}$ infrared absorption method was used for measuring the mixture concentration, and the laser beam passed through near the inner wall of the porous cylinder (approx. $0.1 \mathrm{~mm}$ from the wall). To reduce the thermal effect of the flame or the entrainment of the burnt gas into the light path and to measure the concentration more precisely, two air curtains were set at the outlet of the burner, and plates were set in the porous cylinder for protecting the light path. Moreover, the mixture was diluted with nitrogen to reduce the flame radius. The nitrogen dilution rate $\chi$ is defined as follows:

$$
\chi=\frac{Q_{N 2}}{Q_{f}+Q_{a}+Q_{N 2}} \times 100[\%]
$$

Here, $Q_{f}, Q_{a}$, and $Q_{N 2}$ are the flow rates of fuel, air, and nitrogen, respectively. Since the dilution rate is defined in relation with the mixture flow rate $\left(=Q_{f}+Q_{a}\right)$, the flow rate of nitrogen is constant regardless of the equivalence ratio if $\chi$ is constant; therefore, concentration fluctuations do not affect the flow rate either. In this experiment, the value of $\chi=14 \%$ was chosen.

The fluctuation range of the equivalence ratio is given as $\phi=\phi_{m} \pm a$, where $\phi_{m}$ is mean equivalence ratio and $a$ is amplitude of equivalence ratio. Both $\phi_{m}$ and $a$ were defined at the point of concentration measurement, and the value of $a=0.04$ was chosen throughout the experiment. Frequency of the concentration fluctuation can be chosen from 3 $\mathrm{Hz}$ to $50 \mathrm{~Hz}$. We chose the frequencies of $5 \mathrm{~Hz}$ and $20 \mathrm{~Hz}$ in this experiment.

\subsection{Flame position and burning velocity}

The flame was photographed using a high-speed video camera (SR-1000, frame rate 500FPS, Kodak), and the flame radius was determined by image analysis. The spatial resolution of the image was $0.08 \mathrm{~mm}$. The flame position was defined as the point with the highest luminosity along the radial direction, and the flame radius was calculated as the average value over the circumference of the flame. The flame luminosity was obtained by averaging the luminosity (256-step gradation) of data points recognized as the flame position.

Burning velocity was calculated as follows. By letting the stagnation point (flame central axis) be the origin, the upstream direction be positive, velocity of movement of the 
flame be $u_{f}$, and the unburnt gas velocity at the flame position be $u_{g}$, the burning velocity $S u$ is given as

$$
S u=u_{f}-u_{g}
$$

Here, letting $r_{f}$ be the flame radius and $t$ be time, $u_{f}$ is given as follows.

$$
u_{f}=\frac{d r_{f}}{d t}
$$

Since it is difficult to measure the flow field in the cylinder because of the structure of the burner, $u_{g}$ was calculated by approximating the flow field as a potential flow. In that case, $u_{g}$ is given as follows:

$$
u_{g}=-g \cdot r_{f}
$$

Here, $g$ is the velocity gradient in the radial direction. Since the radius of the porous cylinder is $R=8 \mathrm{~mm}$ and the percolation rate is $U=40 \mathrm{~cm} / \mathrm{sec}$ in this experiment, we obtain $g=U / R=50 \mathrm{sec}^{-1}$.

\subsection{Flame stretch rate}

The flame stretch rate was calculated as follows.

If the density is constant, then by taking the velocity gradient of the flow, flame curvature, and the unsteadiness of the flame into account, the stretch rate at the flame position is given as follows ${ }^{(15)}$ :

$$
\varepsilon=-(n \cdot \nabla)(V \cdot n)-(V \cdot n)(\nabla \cdot n)+v_{n}(\nabla \cdot n)
$$

Here, $\boldsymbol{V}$ is the velocity vector of the flow field, $\boldsymbol{n}$ is the unit vector in the vertical direction to the flame surface, and $v_{n}$ is the velocity of movement of the flame. On the right side, the first term represents the stretch rate based on the velocity gradient, the second term on the flame curvature, and the third term on movement of the flame. When letting them be $\varepsilon_{v g}, \varepsilon_{c u}$, and $\varepsilon_{m o}$, respectively, and the velocity components in a cylindrical coordinate system $(r, \theta$, $z)$ be $\boldsymbol{V}\left(v_{r}, v_{\theta}, v_{z}\right)$, we obtain:

$$
v_{r}=-g \cdot r, \quad v_{\theta}=0, \quad v_{z}=2 \cdot g \cdot z
$$

and when evaluating each term at the flame position $r=r_{f}$, we obtain:

$$
\begin{array}{ll}
\varepsilon_{v g}=-\left.\frac{\partial}{\partial r} v_{r}\right|_{r=r_{f}}=g=50 & {\left[\mathrm{sec}^{-1}\right]} \\
\varepsilon_{c u}=-\left.v_{r} \frac{1}{r}\right|_{r=r_{f}}=g=50 & {\left[\mathrm{sec}^{-1}\right]} \\
\varepsilon_{m o}=-\left.v_{n} \frac{1}{r}\right|_{r=r_{f}}=v_{n} \frac{1}{r_{f}}=\frac{1}{r_{f}} \frac{d r_{f}}{d t} & {\left[\mathrm{sec}^{-1}\right]}
\end{array}
$$

Therefore, the first and second terms are constant at $\varepsilon_{v g}=\varepsilon_{c u}=50 \mathrm{sec}^{-1}$, and only the third term, the stretch rate based on movement of the flame, may vary with the flame radius $r_{f}$ and velocity of movement of the flame $\mathrm{d} r_{f} / \mathrm{d} t$. 


\section{Experimental results and discussion}

\subsection{Static flame}

Figs. 3 and 4 show the equivalence ratio dependencies of burning velocity $S u_{0}$, flame radius $r_{f o}$, thickness of the flame zone $\delta_{f 0}$, and flame luminosity $L_{f 0}$ of the static methane/air flame and the static propane/air flame, respectively. They were calculated by assuming that $\delta_{f 0}$ is nearly the same as the adiabatic one-dimensional flame and using the following formula ${ }^{(16)}$ :

$$
\delta_{f 0}=\frac{\lambda}{c_{p} \rho_{u} S u_{0}}
$$

Here, $\lambda, c_{p}$, and $\rho_{u}$ are the thermal conductivity, the specific heat at constant pressure, and the density of the mixture, respectively. The value of $\lambda$ was calculated using Brokaw's empirical formula ${ }^{(17)}$. Under the conditions of this experiment, when looking at the values of $r_{f 0}$ for the lean flammability limit and the rich flammability limit of the methane flame and the propane flame, in the case of the methane flame, $r_{f 0}$ of the lean flammability limit is smaller than that of the rich flammability limit, but this tendency is reversed in the case of the propane flame. This is attributed to the Lewis number $L e$ (=thermal diffusivity/diffusion coefficient of deficient reactant) effect ${ }^{(2),(3)}$. The lean methane flame and rich propane flame, which have a Lewis number of $L e<1$, can be maintained with smaller flame radius, since the flame is intensified and less likely to extinguish. On the other hand, the rich methane flame and lean propane flame, which have a Lewis number of $L e>1$, extinguish at a relatively large $r_{f o}$, since the flame is attenuated due to the Le effect. When comparing the flame radius $r_{f 0}$ and thickness of the flame zone $\delta_{f 0}$ of the lean flammability limit and rich
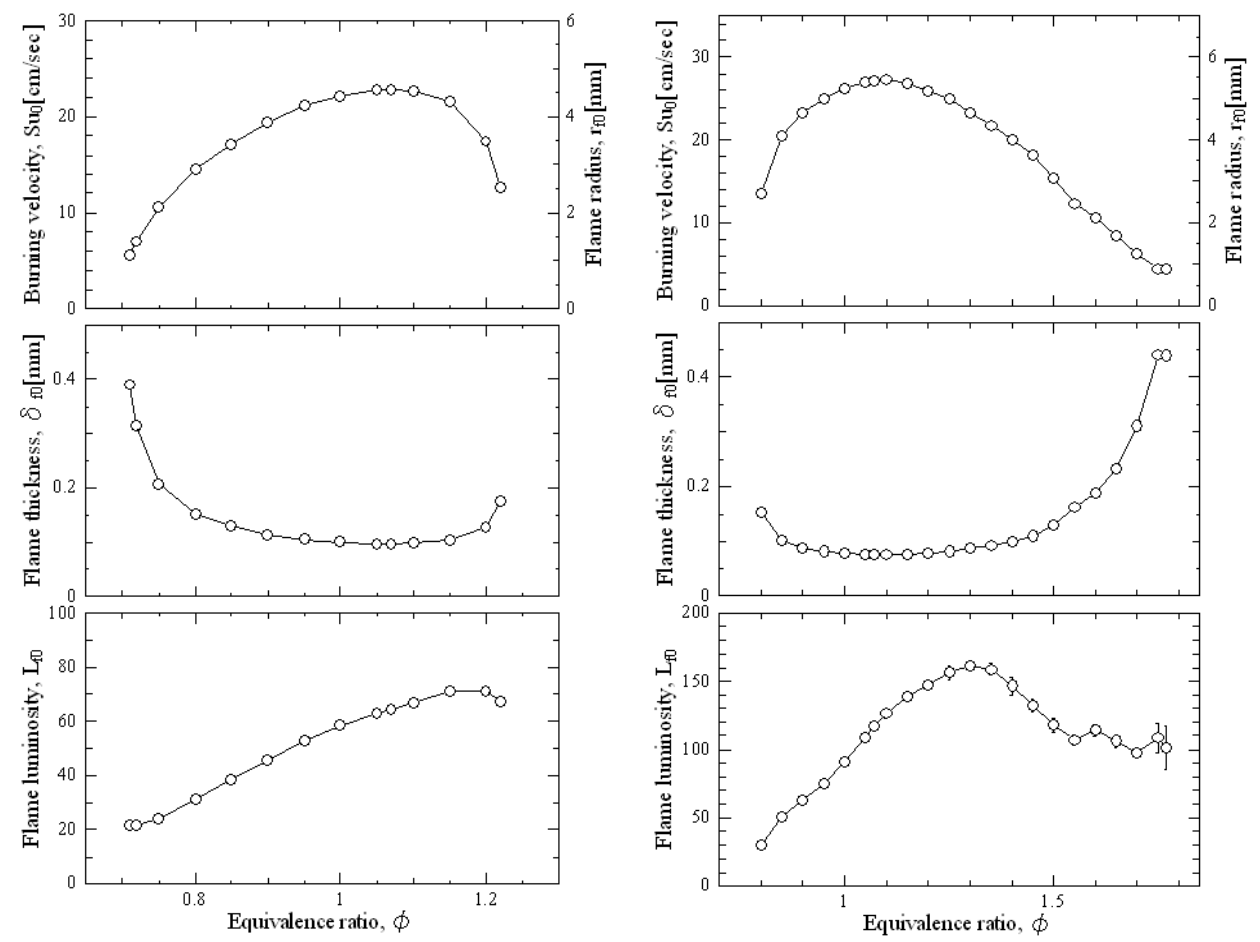

Fig. 3 Equivalence ratio dependencies of burning velocity, flame thickness and flame luminosity of the static methane/air flame $(\chi=14 \%)$.

Fig. 4 Equivalence ratio dependencies of burning velocity, flame thickness and flame luminosity of the static propane/air flame $(\chi=14 \%)$ 
flammability limit, the values of $r_{f 0}$ are 2 to 2.5 times greater than those of $\delta_{f 0}$ for the lean methane flame and rich propane flame, which correspond to $L e<1$. While in the case of the rich methane flame and lean propane flame, which correspond to $L e>1$, the values of $r_{f o}$ are 12 to 18 times greater than $\delta_{f 0}$; there is a great difference between them.

\subsection{Propagation characteristics of dynamic methane flame}

This study aims to investigate the characteristics of the cylindrical premixed flame in relation to equivalence ratio fluctuations near the lean flammability limit. Since the flame curvature affects these characteristics, to change the flame radius, the experiment was performed with varying values of mean equivalence ratio $\phi_{m}$. Figs. 5 and 6 show time variations of equivalence ratio $\phi$ on the inner wall of the porous metal cylinder, flame radius $r_{f}$, burning velocity $S u$, flame luminosity $L_{f}$, and flame stretch rate $\varepsilon$ of the dynamic methane flame at a frequency of $f=20 \mathrm{~Hz}$ and $\phi_{m}=0.75$ and 0.72 , respectively. Time on the horizontal axis is given by dividing the actual time $t$ by period $T$. For comparison, maximums of the flame radius $r_{f 0}$, burning velocity $S u_{0}$, flame luminosity $L_{f 0}$ of the static flame in the range of equivalence ratio and the minimums of the same are also shown. However, as for equivalence ratio fluctuations for $\phi_{m}=0.72$, since the static flame corresponding to the equivalence ratio of $\phi=0.68$, at which the flame becomes the leanest, could not be formed, the minimum corresponding thereto is not shown in Fig. 6. In addition, these figures also show the values $r_{f 0, l l}, S u_{0, l l}$, and $L_{f 0, l l}$ of the static methane flame at the lean flammability limit $(\phi=0.71)$. In the case of $\phi_{m}=0.75$, these values are the same as $r_{f 0, \min }$, $S u_{0, \min }$, and $L_{f 0, \min }$, respectively.

According to the result of $\phi_{m}=0.75$ in Fig. 5, it can be found that the fluctuation amplitude of $S u$ and $L_{f}$ became larger than the variation width of the static flame in the range of equivalence ratio. Following are the reasons, as also shown in the previous reports $^{(11)-(14)}$ : the flame moves as the equivalence ratio fluctuates, and the concentration distribution at the flame front differs from that of the static flame, since the velocity of upstream or downstream movement of the flame increases as the fluctuation frequency increases; thus, the incoming mass flux of deficient reactants when the flame moves upstream is greater than that of the static flame and opposite when moving downstream. Accordingly, the fluctuation amplitudes of $S u$ and $L_{f}$ become larger than those of the static flame. However, while the maximum and minimum of $S u$ and the burnt gas temperature for the planar flame or cylindrical flame with a small curvature in these studies could clearly be seen, both minimums of $S u$ and $L_{f}$ could not be clearly seen under the condition of $\phi_{m}=$ 0.75. According to the relationship between $\phi$ and $L_{f 0}$ of the static flame (Fig. 3), the amount of change in $L_{f 0}$ decreases as $\phi$ becomes lean; therefore, it can be assumed that the minimum of $L_{f}$, is not likely to be seen clearly. The minimum of $S u$, on the other hand, could not be seen clearly despite the fact that the amount of change in $S u_{0}$ increases as $\phi$ becomes lean in the static flame (Fig. 3). The flame curvature and the flame stretch rate can be considered relative to the reason why the minimum of $S u$ could not be seen clearly. That is, since $r_{f}$ around the minimum of $S u$ is decreasing, the direction of diffusion of the reactants to the flame is the same as the direction of movement of the flame. Hence, $S u$ becomes smaller than $S u_{0, m i n}$, since the incoming mass flux of deficient reactants to the flame decreases and the flame temperature falls. Meanwhile, Le number $(<1)$ effect increases as $r_{f}$ decreases, and the flame is intensified. Moreover, the $L e$ effect attributed to the stretch rate $\varepsilon$ works at the same time. In general, the flame of $L e<1$ is intensified as $\varepsilon$ increases, but in the range where $r_{f}$ is small, it is possible for the flame to be attenuated due to incomplete combustion ${ }^{(2)}$. In fact, the values of $S u$ and $L_{f}$ were lower than the values for the lean flammability limit of the static flame $S u_{0, l l}$ and $L_{f 0, l l}$, and thus, it is difficult to discuss the effect of the stretch rate on the flame intensity. However, the value of $\varepsilon$ is nearly constant in the time range where $S u$ becomes minimum, and the stretch rate is also 

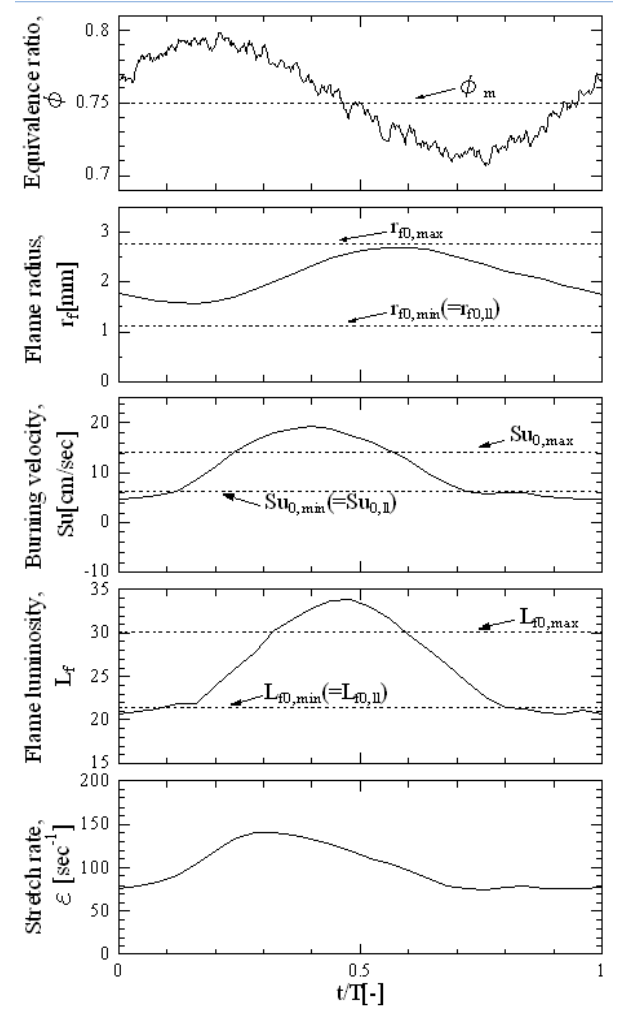

Fig. 5 Time variations of equivalence ratio, flame radius, burning velocity, flame luminosity and flame stretch rate of methane/air flame $\left(\varphi_{m}=0.75, a=0.04, f=20 \mathrm{~Hz}\right)$
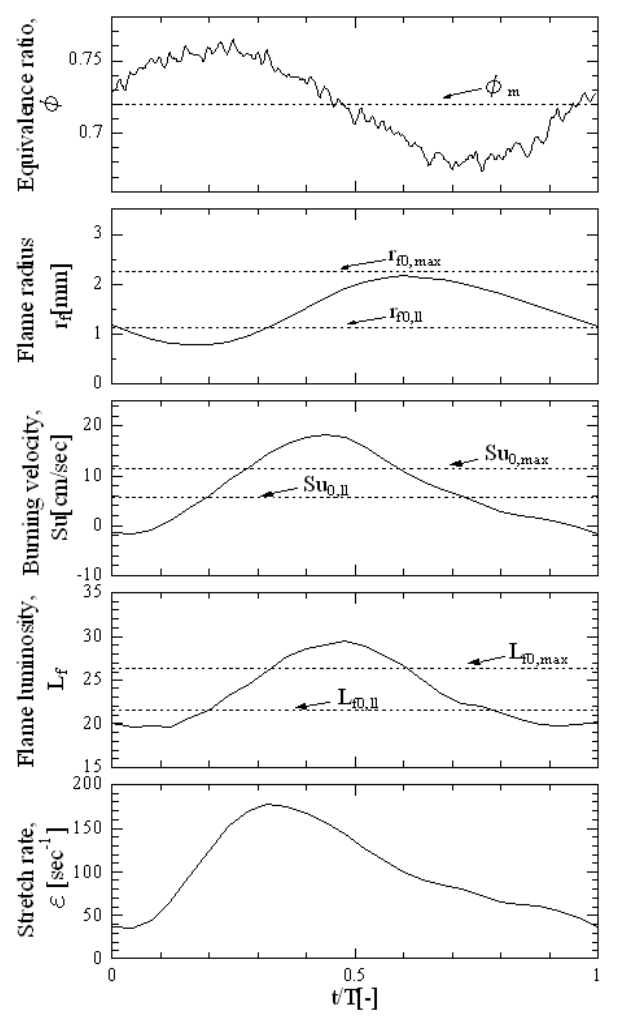

Fig. 6 Time variations of equivalence ratio, flame radius, burning velocity, flame luminosity and flame stretch rate of methane/air flame ( $\phi_{m}$ $=0.72, a=0.04, f=20 \mathrm{~Hz}$ ).

thought to affect $S u$. These can be said to have caused the minimum of $S u$ to be unclear.

In the case of $\phi_{m}=0.72$ in Fig. 6 , where the flame was leaner, there was a time when the value of $r_{f}$, in addition to $S u$ and $L_{f}$, became smaller than the values at the lean flammability limit of the static flame. Especially $S u$ and $L_{f}$ were smaller than the values for the static flame for even a time range of half a period. Moreover, the value of $S u$ was negative around the minimum, and the flame lost its propagation ability. Since the static flame in such a situation cannot be maintained, this result indicates that the extinguishing flame can be recovered by generating equivalence ratio fluctuations, and as the result, the lean flammability limit extends. According to the conventional numerical studies about the response of the flame to sinusoidal equivalence ratio fluctuations, the flammability limit of the dynamic flame extends toward the lean range when the frequency is $100 \mathrm{~Hz}$ or higher $^{(9),(10)}$. In this study, however, it was shown that the lean flammability limit can be extended even at a lower frequency than in these numerical studies. As for the causes of such flame recovery and extension of the lean flammability limit, we must also consider the aforementioned increase of the Le number effect accompanied by reduction of the flame radius (an effect of intensifying the flame), the $L e$ number effect resulting from the flame stretch rate, decrease in the flame-incoming mass flux because of the downstream movement of the flame (an effect of attenuating the flame), in addition to the back support effect of heat and diffusion of radicals from behind the flame, which have been shown in the above numerical studies ${ }^{(8)-(10)}$. That is, in the case of the lean range fluctuations as in this study, fuel concentration in the mixture also decreases when $S u$ decreases, and the burnt gas temperature and the radical concentration behind the flame are higher than those corresponding to the mixture concentration to be flowing into the flame ${ }^{(8)}$. The upstream 
diffusion of heat and radicals gives a back support effect that supports the flame from behind against the inflowing lean mixture into the flame, which the static flame cannot maintain.

Figs. 7 and 8 show the range of flame movement against $\phi_{m}$ and the range of the stretch rate, respectively. These figures show the frequencies of $5 \mathrm{~Hz}$, which has a smaller dynamic effect, and $20 \mathrm{~Hz}$, which has a greater dynamic effect. In Fig. 7, both in $f=5 \mathrm{~Hz}$ and $20 \mathrm{~Hz}$, the fluctuation amplitudes were approximately same regardless of $\phi_{m}$. In addition, the range of flame movement increased as $\phi_{m}$ decreased. This is based on the comparison with the relationship between equivalence ratio $\phi$ and the flame radius $r_{f o}$ of the static flame. Moreover, since the range of flame movement increases as $\phi_{m}$ decreases, the fluctuation amplitude of the stretch rate $\varepsilon$ also increases, as shown in Fig. 8. However, while the difference in the fluctuation amplitude of $\varepsilon$ because of the difference in $f$ is small when $\phi_{m}$ is large, the difference in the amplitude increases as $\phi_{m}$ decreases, and the fluctuation amplitude at $\phi_{m}=0.72$ and $f=20 \mathrm{~Hz}$ is much greater than the stretch rate with no fluctuations $\left(=100 \mathrm{sec}^{-1}\right)$. Flame recovery in Fig. 6 could be seen when the stretch rate widely fluctuated, $S u$ was negative, and $\varepsilon$ was minimum. This decrease in the stretch rate may be one of the main causes that prevented the flame from extinguishing completely.

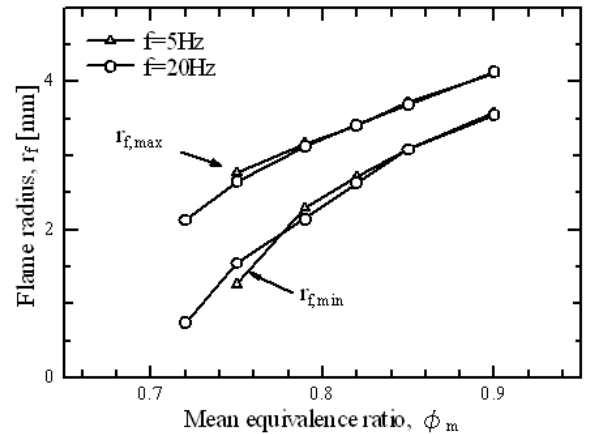

Fig. 7 Range of flame movement against mean equivalence ratio in methane/air flame $(a=0.04)$.

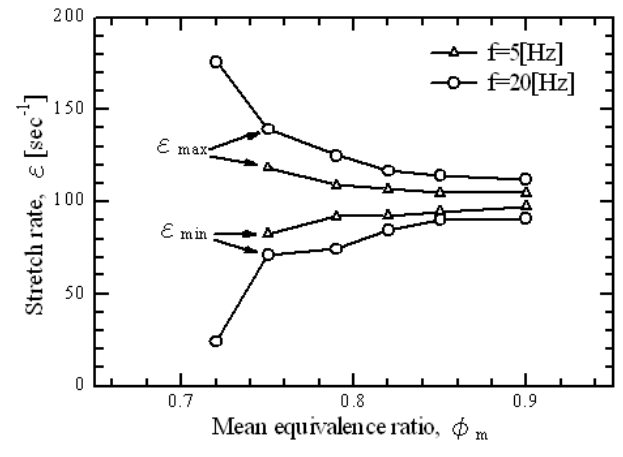

Fig. 8 Range of stretch rate fluctuation against mean equivalence ratio in methane/air flame $(a=0.04)$.

\subsection{Extinction characteristics of dynamic methane flame}

As $\phi_{m}$ decreased from the value in the preceding section, the flame would eventually not be formed at all. In the course of this transition, there were some cases where the flame was formed at first but extinguished in the middle of the measurement.

Figs. 9 and 10 show time variations of the flame radius $r_{f}$, burning velocity $S u$, flame luminosity $L_{f}$, and stretch rate $\varepsilon$ right before the extinction at $f=5 \mathrm{~Hz}$ and $20 \mathrm{~Hz}$, respectively. It can be seen that regardless of $f$ the flame came to extinction while $r_{f}$ decreased. Although it was not clear in $5 \mathrm{~Hz}, S u$ and $L_{f}$ were increasing at the time of extinction. That is, the flame extinguished in spite of the fact that the mixture that intensifies the flame was flowing into the flame. The flame radius $r_{f}$ at the time of extinction was $0.4-0.5 \mathrm{~mm}$, which is almost the same as the flame thickness at the lean flammability limit $\delta_{f 0}$ shown in Fig. 3. It could also be seen by the flame observation using a high-speed video camera that the flame right before its extinction was no longer cylindrical but rod-like. Based on the above situations, this extinction is considered to have been due to incomplete combustion caused by the flame being pushed against the stagnation plane (in this study, central axis of the flame), as shown in the study by Yamaoka and Tsuji ${ }^{(2)}$.

Next, when comparing the results of $5 \mathrm{~Hz}$ and $20 \mathrm{~Hz}$, in $5 \mathrm{~Hz}$, although the minimums of $S u$ and $L_{f}$ are greater than those in $20 \mathrm{~Hz}$, there was no flame recovery seen. The 
abovementioned back support effect being small because of the smaller frequency compared to $20 \mathrm{~Hz}$ is considered to be a cause, but the phase difference between $r_{f}$ and $S u$ is also considered relevant. As seen in Figs. 9 and 10, $r_{f}$ and $S u$ in $20 \mathrm{~Hz}$ had a greater phase difference than that in $5 \mathrm{~Hz}$. Su in $20 \mathrm{~Hz}$ was slightly greater at the time when $r_{f}$ became the minimum, than the burning velocity $S u_{0}, l l$ of the static flame at the lean flammability limit. This means that the mixture with enough concentration to intensify the flame was flowing into the flame even when $r_{f}$ decreased to a degree that it causes incomplete combustion, and thus, the flame was not likely to extinguish.
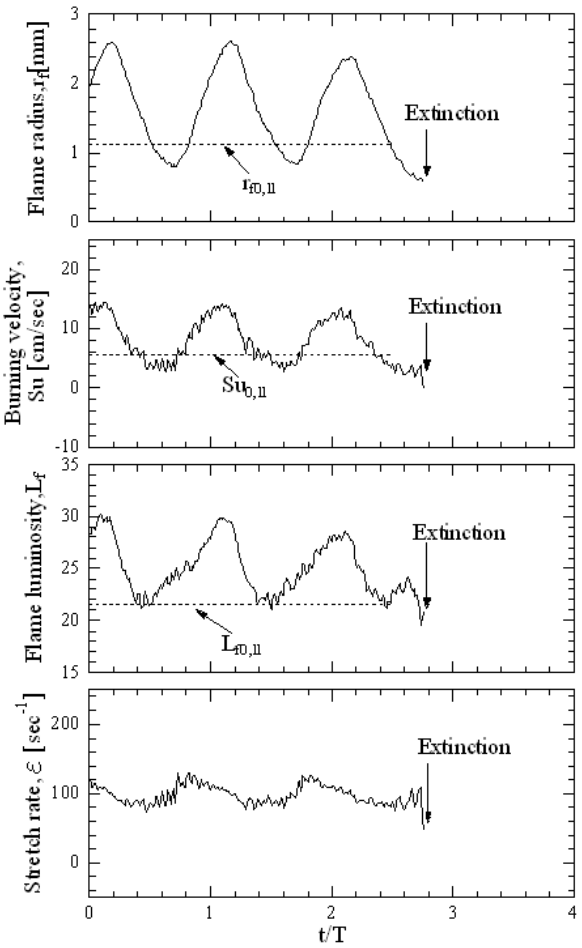

Fig. 9 Time variations of burning velocity, flame luminosity and flame stretch rate of methane/air flame $\left(\varphi_{m}=0.73, a=0.04, f=5 \mathrm{~Hz}\right)$
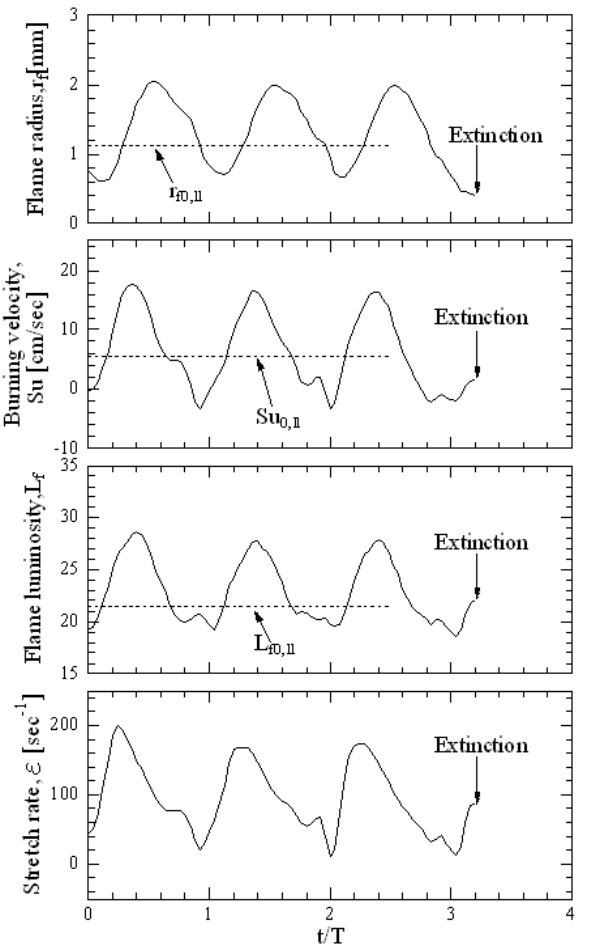

Fig. 10 Time variations of burning velocity, flame luminosity and flame stretch rate of methane/air flame $\left(\varphi_{m}=0.715, a=0.04, f=20 \mathrm{~Hz}\right)$

\subsection{Effect of type of fuel on extinction}

Fig. 11 shows time variations of the flame radius $r_{f}$, burning velocity $S u$, flame luminosity $L_{f}$, and stretch rate $\varepsilon$ of the propane flame right before its extinction at $f=20$ Hz. In the figure, $r_{f 0, l l}, S u_{0, l l}$, and $L_{f 0, l l}$ indicate the values for the static propane flame at the lean flammability limit ( $\phi=0.8$ ). It can be seen that in the case of the propane flame, as in the case with the methane flame, the flame was maintained by generating equivalence ratio fluctuations even when the flame radius decreased to a degree that the static flame could not be maintained. However, $r_{f}$ at the time of extinction is larger than that in the methane flame. Based on the result of $S u$, a phenomenon such as recovery of the flame that lost its propagation ability, as seen in the methane flame in the time range of a few periods before the extinction, could not clearly be seen. Moreover, right before the extinction, although $r_{f}$ monotonously decreased and the flame came to an extinction as in the case of the methane flame, $S u$ and $L_{f}$ were not clearly increasing. As mentioned above, in the case of the lean propane flame, the flame is attenuated since $L e>1$, and the flame is further attenuated as $r_{f}$ decreases, since the flame is cylindrical. Therefore, the flame is not recovered even if the mixture that intensifies the flame flows into the flame, and $S u$ and $L_{f}$ right before the 
extinction are not clearly increasing.

Based on the above facts, extension of the flammable range of the dynamic cylindrical premixed flame and flame recovery, which causes the extension, are thought to be attributed in a complex manner to Le number effect, which is closely related to the flame radius; increase and decrease in incoming mass flux of the mixture to the flame resulted from the direction of movement of the flame; a back support effect by heat and radicals in the burnt gas; a flame stretch effect; and an effect of phase difference between the flame diameter and the mixture concentration flowing into the flame. Hereafter, further studies about each of these effects on flame recovery are required.
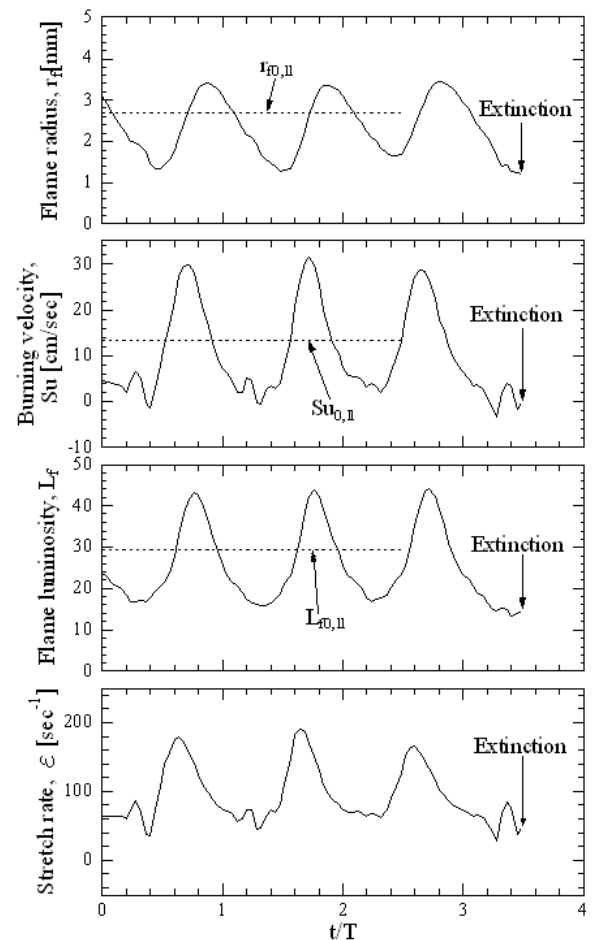

Fig. 11 Time variations of burning velocity, flame luminosity and flame stretch rate of propane/air flame $\left(\varphi_{m}=0.815, \quad a=0.04, f=20 \mathrm{~Hz}\right)$

\section{Conclusion}

We experimentally studied about propagation and extinction of the methane/air and propane/air cylindrical flame diluted with nitrogen and given periodic equivalence ratio fluctuations around the lean flammability limit, and found out the following.

(1) Fluctuation amplitude of burning velocity or flame luminosity when fluctuating equivalence ratio is larger than the range of the same for the flame that has static equivalence ratio (static flame). In addition, as mean equivalence ratio becomes lean with a constant fluctuation amplitude, the minimum of burning velocity or flame luminosity becomes unclear.

(2) The flame that has equivalence ratio fluctuations can be maintained even when its burning velocity and flame luminosity become smaller than those for the static flame at the lean flammability limit.

(3) Depending on the fluctuation frequency, even when burning velocity becomes negative (the flame loses its propagation ability) at some time in a period, the flame recovers by being intensified by equivalence ratio fluctuations.

(4) The methane flame, which is intensified by the Lewis number effect, is more likely 
to be recovered than the attenuated propane flame.

\section{References}

(1) Peter, N., Laminar Flamelet Concepts in Turbulent Combustion, Proceedings of the Combustion Institute, Vol.21: (1986), pp.1231-1250.

(2) Yamaoka, I. and Tsuji, H., Structure and Extinction of Near-Limit Flames in a Stagnation Flow, Proceedings of the Combustion Institute, Vol.19: (1982), pp.1231-1250.

(3) Sato, J., Effects of Lewis Number on Extinction Behavior of Premixed Flames in a Stagnation Flow, Proceedings of the Combustion Institute, Vol.19: (1982), pp.1541-1548.

(4) Kobayashi, H. and Kitano, M, Extinction Characteristics of a Stretched Cylindrical Premixed Flame, Combustion and Flame, Vol.76: (1989), pp.285-295.

(5) Kobayashi, H. and Kitano, M., Effects of Equivalence Ratio on the Extinction Stretch Rate of Cylindrical Premixed Flames, Combustion Science and Technology, Vol.89: (1993), pp.253-263.

(6) Egolfopoulos, F. N., Dynamics and Structure of Unsteady, Strained, Laminar Premixed Flames, Proceedings of the Combustion Institute, Vol.25: (1994), pp.1365-1373.

(7) Hirasawa, T., Ueda, T., Matsuo, A. and Mizomoto, M., Effect of Oscillatory Stretch on the Flame Speed of Wall-Stagnating Premixed Flame, Proceedings of the Combustion Institute, Vol.27: (1998), pp.875-882.

(8) Marzouk, Y. M., Ghoniem, A. F. and Najm, H. N., Dynamic Response of Strained Premixed Flames to Equivalence Ratio Gradients, Proceedings of the Combustion Institute, Vol.28: (2000), pp.1859-1866.

(9) Lauvergne, R. and Egolfopoulos, F. N., Unsteady Response of C3H8/Air Laminar Premixed Flames Submitted to Mixture Composition Oscillations, Proceedings of the Combustion Institute, Vol.28: (2000), pp.1841-1850.

(10) Sankaran, R. and Im, H. G., Dynamic Flammability Limits of Methane/Air Premixed Flames with Mixture Composition Fluctuations, Proceedings of the Combustion Institute, Vol.29: (2002), pp.77-84.

(11) Suenaga, Y., Kitano, M., Yanaoka, H. and Fujita, N., Characteristics of the Flame Propagating through a Mixture Flow with Periodic Concentration Fluctuation, Transactions of the Japan Society of Mechanical Engineers, Series B, Vol.69: (2002), pp.2138-2143. (in Japanese).

(12) Suenaga, Y., Kitano, M., Yanaoka, H. and Fujita, N., Response of a Premixed Flame to Equivalence Ratio Fluctuation in Stagnation Flow, Journal of the Combustion Society of Japan, Vol.45, No.134: (2003), pp.229-237. (in Japanese).

(13) Suenaga, Y., Kitano, M., Yanaoka, H. and Fujita, N., Characteristics of the Flame Propagating through a Mixture Flow with Periodic Concentration Fluctuation (Effects of Concentration Fluctuation Range on Flame Characteristics), Transactions of the Japan Society of Mechanical Engineers, Series B, Vol.71: (2005), pp.1190-1196. (in Japanese).

(14) Takahashi, Y., Suenaga, Y., Kitano, M. and Kudoh, M., Response of a Cylindrical Premixed Flame to Periodic Concentration Fluctuation, Transactions of the Japan Society of Mechanical Engineers, Series B, Vol.71: (2005), pp.3046-3052. (in Japanese).

(15) Matalon, M., On Flame Stretch, Combustion Science and Technology, Vol.31:(1983), pp.169-181.

(16) Mizutani, Y., Nensho Kougaku (Combustion Engineering, Second Edition), (1989), pp.82-85. (in Japanese).

(17) Hirschferder J.O., Curtiss C.F., and Bird R.B., Molecular Theory of Gases and Liquids, (1954), pp.508-510. (in Japanese) 